\title{
The effect of needleless electrospun nanofibrous interleaves on mechanical properties of carbon fabrics/epoxy laminates
}

\author{
K. Molnár ${ }^{1,2 *}$, E. Košt'ákováa ${ }^{3}$, L. Mészáros ${ }^{1}$ \\ ${ }^{1}$ Department of Polymer Engineering, Faculty of Mechanical Engineering, Budapest University of Technology and \\ Economics, Müegyetem rkp. 3., H-1111, Budapest, Hungary \\ ${ }^{2}$ MTA-BME Research Group for Composite Science and Technology, Müegyetem rkp. 3., H-1111, Budapest, Hungary \\ ${ }^{3}$ Department of Nonwovens, Faculty of Textile Engineering, Technical University of Liberec, Hálkova 6, 46117 Liberec \\ Czech Republic
}

Received 3 June 2013; accepted in revised form 11 September 2013

\begin{abstract}
The effect of polyacrylonitrile nanofibrous interlaminar layers on the impact properties of unidirectional and woven carbon fabric (CF)-reinforced epoxy (EP) matrix composites was investigated. The nanofibers were produced directly on the surface of carbon fabrics by a needleless electrospinning method, and composites were then prepared by vacuum-assisted impregnation. Interlaminar shear stress tests, three-point bending, Charpy-impact and instrumented falling weight tests were carried out. The fracture surfaces were analyzed by scanning electron microscopy. Due to the nano-sized reinforcements, the interlaminar shear strength of the woven and unidirectional fiber-reinforced composites was enhanced by 7 and $11 \%$, respectively. In the case of the falling weight impact tests carried out on woven reinforced composites, the nanofibers increased the absorbed energy to maximum force by $64 \%$ compared to that measured for the neat composite. The Charpy impact tests indicated that the nanofiber interleaves also led to a significant increase in the initiation and total break energies. Based on the results, it can be concluded that the presence of nanofibers can effectively increase the impact properties of composites without compromising their in-plane properties because the thickness of the composites was not altered by the presence of interleaves. The improvement of the impact properties can be explained by the good load distribution behavior of the nanofibers.
\end{abstract}

Keywords: polymer composites, needleless electrospinning, carbon fiber, nanofiber, delamination

\section{Introduction}

The relatively easy production of polymer nanofibers by electrospinning has been the subject of many application-oriented investigations over the past few years. Most of these studies address the possibility of using such nanofibers in filtering, biomedical, sensor and clothing applications [1-4]. Because of their high surface-area-to-volume ratio, the nanofibrous materials could also be efficient reinforcing materials in polymer matrix composites. In these systems, the nanofibers can even act as the primary reinforcement (the nanofibers are the only reinforc- ing materials) as well as co-reinforcement (in addition to microfibers) [5]. From a mechanical properties point of view, the main problem associated with common fiber-reinforced polymer composite laminates is their weak interlaminar properties. Due to a geometry that is not absolutely planar, much free space occurs between layers of the reinforcing structures, which are filled up by the matrix material during impregnation. Thus, between the layers, the properties are determined mainly by the matrix and voids. The loads induced by shear- or out-of-plane stresses must be borne by this relatively weak matrix,

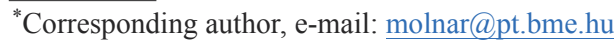

(C) BME-PT
} 
and therefore, damage such as delamination, buckling and peeling can occur $[6,7]$. It should also be noted that the physical properties of the matrix can also be affected by the change in several environmental factors such as temperature or humidity [8] that can result in the further decrement of interlaminar properties.

There are several technologies that have been developed to enhance the interlaminar shear strength of polymer composites, such as physical blending, the placement of special thin films [9-11] and the incorporation of carbon nanotubes (CNTs), alumina or silica particles between laminate layers [12-14]. However, these techniques often modify the geometry and increase the weight of laminates. In such cases, improving the interlaminar properties can lead to a decrease of in-plane properties. Stitching [15], z-fiber pinning and other methods [16] can be applied to clench the layers, but these procedures can cause fiber breaks in the primary reinforcement that can also lead to a decrease in in-plane properties and generate additional production costs.

Using nanofibrous layers can be a feasible way to enhance interlaminar properties without compromising other mechanical properties. Nanofibers can be applied in small amounts, and because they are very flexible, they can take the shape of the microfibrous reinforcement that is applied, locally exerting their effects in matrix-rich areas. Furthermore, because nanofibrous layers are porous, they can be easily soaked in resin; therefore, they do not affect the geometry or the fiber content of composites significantly. The main benefit of using nanofibers in conventional composites is that the load transfer between the strengthening layers becomes more efficient, thus making the matrix between the layers tougher [17].

Interlaminar toughening using small-diameter fibers was first applied at the beginning of 2000s by Dzenis and Reneker [18], who produced graphite/ epoxy unidirectional pre-pregs with poly(benzimidazole) electrospun fibers. The authors measured 15 and $130 \%$ improvements in the Mode I and II critical energy release rates, respectively.

Zhang et al. [19] investigated the effect of the thickness of nanofibrous interleaves and the nanofiber diameters in composites, concluding that finer nanofibers resulted in better improvements in interlaminar properties without altering the in-plane performance of toughened composites.
Chen et al. [20] used electrospun carbon nanofiber mats to modify the interlaminar properties of conventional carbon fiber fabric-reinforced epoxy composites. It was demonstrated that the nanofibrous carbon interleaves could effectively improve the interlaminar and flexural properties of the composites. A significant enhancement in the in-plane and out-ofplane electrical conductivity was observed as well. In another study, Chen et al. [21] achieved superior mechanical properties. The main difference compared to the previous composite was that the nanofibers were collected on the surface of the microfibrous fabrics.

Nanofiber mats can be placed between laminate layers manually or can be deposited by directly spinning them onto the surface of the reinforcement [22, 23]. One of the most efficient technologies for covering a surface with nanofibers is a needleless technology called Nanospider ${ }^{\mathrm{TM}}$. This process is based on using an electric field to simultaneously induce numerous polymeric jets from a sufficiently large liquid surface carried on a roller wading in a bath of polymer solution [24].

The positive effects of the interlaminar incorporation of nanofibers have been proved mainly by static mechanical tests; however, the impact properties have not been as widely investigated [19, 23, 25].

The aim of this study was to investigate the interlaminar behavior of carbon fiber-reinforced epoxy matrix composite laminates toughened by electrospun nanofibers. Both unidirectional (UD) and woven carbon fabrics were covered directly by nanofibers and then laminated. The toughening effect was investigated by static mechanical and impact tests and scanning electron microscopy.

\section{Materials and specimen preparation}

For the production of nanofibers, polyacrylonitrile (PAN) copolymer was chosen because of its ductility and good adhesion to epoxy resin, which is a typical matrix material for high-performance carbon fiber-reinforced composites [26, 27]. The PAN supplied by a carbon fiber manufacturer was dissolved in dimethylformamide (DMF, Molar Chemicals, Hungary) with the aid of a magnetic mixer at $50^{\circ} \mathrm{C}$ for 6 hours in a beaker. The optimal concentration of the solution for electrospinning was determined to be $11 \mathrm{wt} \%$ based on our previous experiments [28]. The applied electrospinning setup is shown in Figure 1. Between the rotary spinneret electrode (Fig- 
ure 1. (1)) and the grounded plate electrode (Figure 1. (2)), a moving textile collector was placed (Figure 1. (7)). The distance between the collector and the spinneret was set to $130 \mathrm{~mm}$, and the traction speed of the collector was set to $100 \mathrm{~mm} / \mathrm{min}$ by adjusting the rotation speed of the rollers (Figure 1. (6)). The applied voltage was $70 \mathrm{kV}$ (direct current). Electrospinning was carried out in an air-conditioned chamber, where the temperature and relative humidity were set to $20^{\circ} \mathrm{C}$ and $20 \%$, respectively. A low relative humidity level was set because the formed PAN fibers are very hygroscopic and the moisture in the PAN solution leads to early precipitation and beard formation.

As the primary reinforcement, the unidirectional carbon fabric Panex35 (PX35FBUD300, Zoltek Zrt., Hungary), with an areal density of $333 \mathrm{~g} / \mathrm{m}^{2}$, was selected. In this fabric, the linear density of yarns is 3700 tex and the thread count is $2 / \mathrm{cm}$. The other material selected was Sigratex KDL 8003 (SGL Tech-

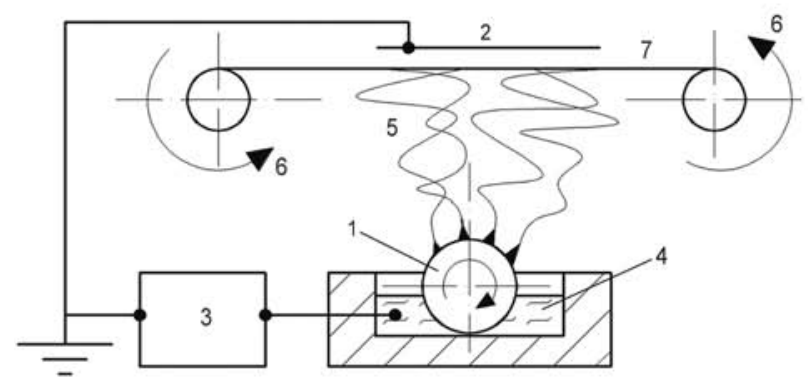

a)

Figure 1. Electrospinning setup used to collect nanofibers on the surface of reinforcing materials. 1: rotary electrode, 2: grounded plate electrode, 3: high-voltage power supply, 4: polymer solution, 5: fiber formation space, 6: rollers, 7: moving belt collector, 8: air inlet, 9: air outlet, 10: chamber.

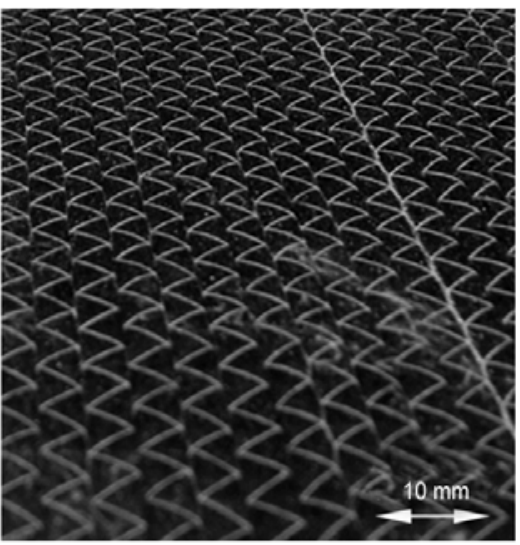

a)

nologies $\mathrm{GmbH}$, Germany), a plain weave carbon fabric with an areal density of $200 \mathrm{~g} / \mathrm{m}^{2}$. In this fabric, the linear density of yarns is 200 tex and the thread count is $5 / \mathrm{cm}$ in both the weft and warp directions.

In this work, different carbon fiber reinforcements were coated directly with nanofibers, indicating that the moving textile collector between the rollers (Figure 1. (6)) was the chosen microfibrous reinforcing fabrics themselves; therefore, nanofibers were produced exactly on the surface of the fabrics. The carbon fabrics were cut into $40 \mathrm{~cm}$-wide strips, attached to the rollers and then coated with nanofibers.

Figure 2 shows the unidirectional carbon fabrics before (Figure 2a) and after electrospinning (Figure $2 b$ ) with a thin white layer of nanofibers.

After the coating process, the carbon fabrics were detached from the rollers and composite preparation procedure was implemented. As the matrix material,

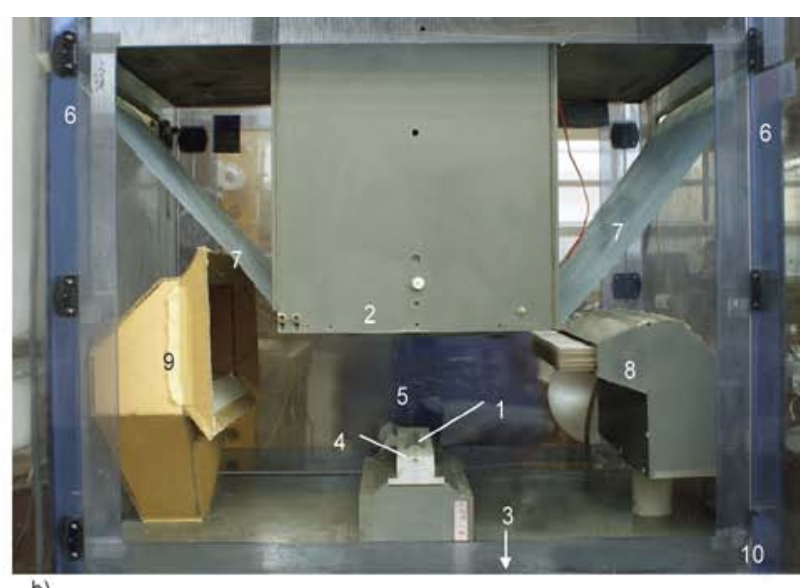

b)

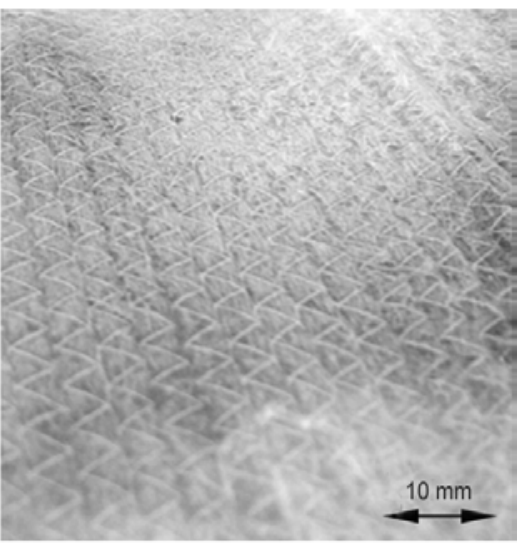

b)

Figure 2. A sample of unidirectional carbon fabric before (a) and after (b) electrospinning 
Table 1. Applied samples, measurement parameters and standards used for mechanical tests. UD: unidirectional, W: woven (fabric)

\begin{tabular}{|l|c|c|c|c|l|}
\hline & $\begin{array}{c}\text { Sample size } \\
{[\mathbf{m m} \times \mathbf{m m}]}\end{array}$ & $\begin{array}{c}\text { Layers of primary } \\
\text { reinforcement }\end{array}$ & $\begin{array}{c}\text { Gauge/span length } \\
{[\mathbf{m m}]}\end{array}$ & $\begin{array}{c}\text { Test/impact speed } \\
{[\mathbf{v a r i a b l e}]}\end{array}$ & \multicolumn{1}{|c|}{ Standard } \\
\hline ILSS & $76.2 \times 12.8$ & 6-ply UD & $25 / 6.35$ & $1.3 \mathrm{~mm} / \mathrm{min}$ & ASTM D3846-94 \\
\hline ILSS & $76.2 \times 12.8$ & 4-ply W & $25 / 6.35$ & $1.3 \mathrm{~mm} / \mathrm{min}$ & ASTM D3846-94 \\
\hline 3PB & $70 \times 15$ & 3-ply UD & 56 & $5 \mathrm{~mm} / \mathrm{min}$ & ISO 14125:1998 \\
\hline 3PB & $50 \times 15$ & 4-ply W & 40 & $5 \mathrm{~mm} / \mathrm{min}$ & ISO 14125:1998 \\
\hline Charpy & $70 \times 10$ & 6-ply UD & 56 & $2.9 \mathrm{~m} / \mathrm{s}$ & ISO 179-2:2000 \\
\hline Charpy & $25 \times 10$ & 4-ply W & 20 & $2.9 \mathrm{~m} / \mathrm{s}$ & ISO 179-2:2000 \\
\hline I-FWIT & $70 \times 70$ & 4-ply W & $\varnothing 20$ & $4.4 \mathrm{~m} / \mathrm{s}$ & ISO 6603-2 \\
\hline
\end{tabular}

FM20-type (P+M Polimerkemia Kft., Hungary) epoxy resin was used, with a T16-type curing agent from the same company. The mass ratio of the components was 100:20 (epoxy:curing agent).

The specimens used for the investigations were produced by the wet hand layup method in a one-sided, polished sheet mold. After impregnation, vacuum pressing in a bag was applied to achieve a higher fiber content and to remove air bubbles. The pressure was set to 0.1 bar and held for 6 hours at $25^{\circ} \mathrm{C}$. Postcuring was carried out at $60^{\circ} \mathrm{C}$ for 4 hours under the same pressure. The same number of reference coupons (without nanofibers) was also produced. To best compare the samples, all samples were prepared together at the same time and under the same curing and heat treatments.

Table 1 summarizes the characterization methods, sample sizes and measurement parameters. Five nanofiber-covered UD layers with one top (noncoated) UD layer $\left[0_{\mathrm{N} 2} / 0\right]$ were laminated for interlaminar shear strength (ILSS) and Charpy measurements. For three-point bending (3PB) testing, three layers with two interleaves $\left[0_{\mathrm{N} 2} / 0\right]$ were used. In the case of the woven reinforcement, four layers of the woven fabric composite (fiber direction: 0 and $90^{\circ}$ ) were laminated with three nanofibrous interleaves $\left[0 \mathrm{~F}_{\mathrm{N} 3} / \mathrm{OF}\right]$ for the same measurements, which were supplemented by instrumented falling dart impact tests.

\section{Mechanical and morphological characterizations}

The composite samples had a thickness of approximately $2.8 \mathrm{~mm}$ in the case of the six-ply UD reinforcement, $1.4 \mathrm{~mm}$ for the three-ply UD reinforcement and $1 \mathrm{~mm}$ in the case of the woven fabric composite. The exact thickness values were evaluated from the measured fiber contents and the densities of the materials. A piece of weighed composite was placed in a ceramic crucible with a known mass. The crucible was heated to $600^{\circ} \mathrm{C}$ in a Nabertherm (Germany) oven and held at this temperature for an hour. From the residual ash mass, the carbon fiber content could be calculated for three individual specimens per sample.

The ILSS and 3PB tests were carried out on a Zwick Z005 (Germany) universal testing machine for seven specimens per sample type. The ILSS was determined by applying a tensile load instead of a compressive load to prevent the samples from buckling. Charpy-impact measurements were carried out on Ceast Resil Impactor Junior (Italy) impact tester equipped with a DAS 8000 data collector. The impact speed was $2.9 \mathrm{~m} / \mathrm{s}$, and the pendulum carried an energy of 2 J. In Charpy Ep (edge, parallel) tests, specimens are hit along the edge parallel to the piles of fibers, whereas in Charpy Fn (face, normal) tests, specimens are hit along the face normal to the direction of fibers. Seven specimens for each kind of sample and direction were investigated.

For the instrumented falling weight impact tests (I-FWIT), specimens were cut from the woven carbon fabric-reinforced laminates in the direction of the fiber orientations (the UD-reinforced composites were not suitable for this test). The measurements were carried out using a Ceast Fractovis (Italy) impact tester equipped with a DAS 8000 data collector to conduct seven measurements per sample type. The diameter of the dart was $20 \mathrm{~mm}$, the diameter of the clamping unit was $40 \mathrm{~mm}$, the falling mass was $23.62 \mathrm{~kg}$, the impact speed was $4.4 \mathrm{~m} / \mathrm{s}$ and the temperature was $23^{\circ} \mathrm{C}$. The tip of the dart was lubricated with silicone oil to reduce the friction between the specimen and the dart. Subcritical impact tests of the specimens were carried out with a $3.62 \mathrm{~kg}$ falling mass carrying $0.6 \mathrm{~J}$ energy using the same equipment; during the measurement, the deformation and adsorbed energy were monitored. After 
the test, the residual deformation was zero; therefore, no fiber break occurred, but the matrix was damaged.

The morphology of the fracture surfaces was studied using a JEOL 6380 LA (Japan) SEM after sputtering the samples with $\mathrm{Au} / \mathrm{Pd}$ alloy.

\section{Results and discussion}

The thickness of the electrospun layer was measured by SEM before impregnation and determined to be $27 \pm 5 \mu \mathrm{m}$. The areal density of the electrospun coating was measured to be $1 \mathrm{~g} / \mathrm{m}^{2}$. On the one hand, thicker interleaves may improve the quality of toughening [19]; on the other hand, they can significantly alter the cross-section of composites, therefore reducing their in-plane strength. The diameters of 250 nanofibers were determined based on the SEM images using the UTHSCSA Image Tool 3.0 software program. The average nanofiber diameter was determined to be $195 \pm 46 \mathrm{~nm}$.

\subsection{Fiber content}

The results of carbon fiber content measurements, quasi-static ILSS and flexural tests for different types of composite samples are summarized in Table 2.

The carbon fiber content was approximately $50 \mathrm{wt} \%$ (approx. $38 \mathrm{~V} \%$ ) for each composite, which corresponds to the expected content. The type of reinforcing structure (UD or woven) and the presence of nanofibers (representing only 0.1 and $0.2 \mathrm{~V} \%$ in the case of UD and woven reinforced composites, respectively) did not affect the fiber content; therefore, the results of the mechanical tests are comparable. The standard deviation of the carbon fiber weight is greater than the total weight of the nanofibers within the specimens; thus, the presence of nanofibers, in terms of the weight and size of the composites, was non-significant. It can also be con- cluded that the presence of the nanofibers did not change the quality of the impregnation.

\subsection{Interlaminar shear strength}

The interlaminar shear strength of the composites was observed to increase when nanofibers were used. The strengths of the unidirectional and woven fabric-reinforced composites were enhanced by 11 and $7 \%$, respectively. It should be noted that the changes in the standard deviations were even more notable. The standard deviations decreased by 73 and 56\%, respectively, which indicates that nanofibers made the failure process more uniform, which can be explained by the fact that the nanofibers could distribute the stress in-plane. Figure 3 shows SEM images of the fracture surfaces after the ILSS tests.

The images reveal that nanofibers could toughen the matrix. In the case of the reference materials, separation of the matrix and the carbon fibers (Figure $3 \mathrm{a} ; 3 \mathrm{~d}$ ) occurred. The fracture surfaces appear rigid, and the fragmentation of the matrix into numerous pieces with sharp edges and no plastic deformation can be observed. In the case of the nanofibrous reinforcement (Figure 3b; 3e), the matrix partly remained on the surface of the primary reinforcement. The images suggest that after the fabrication of the composite, the nanofibers remained uniformly distributed between the reinforcing layers. Fracture occurred within the matrix, and the fracture surface became more structured than it was in the reference material in both cases. Overall, the nanofiber-containing matrix could distribute more stress and transmit the load toward the carbon fibers, thus changing the type of delamination that occurred and resulting in higher shear strength with a lower standard deviation, respectively.

The connection between the nanofibers and the matrix material was investigated at higher magnification (Figure 3c; 3f). In the case of the UD-rein-

Table 2. Interlaminar shear strength and flexural properties of composites with and without nanofibrous interleaves (UD CFRP: unidirectional carbon fiber-reinforced polymer; UD CFNRP: unidirectional carbon fiber and nanofiber-reinforced polymer; W CFRP: woven carbon fiber-reinforced polymer; W CFNRP: woven carbon fiber- and nanofiber-reinforced polymer)

\begin{tabular}{|c|c|c|c|c|}
\hline & UD CFRP & UD CFNRP & W CFRP & W CFNRP \\
\hline Carbon fiber content [wt $\%]$ & $50.5 \pm 2.1$ & $50.4 \pm 0.5$ & $51.7 \pm 0.8$ & $50.7 \pm 2.5$ \\
\hline ILSS [MPa] & $11.4 \pm 1.9$ & $12.7 \pm 0.5$ & $13.3 \pm 1.5$ & $14.3 \pm 0.7$ \\
\hline Change in ILSS [\%] & & $+11 \%$ & & $+7 \%$ \\
\hline Flexural strength [MPa] & $778 \pm 86$ & $945 \pm 61$ & $610 \pm 23$ & $534 \pm 65$ \\
\hline Change in flexural strength [\%] & & $+21 \%$ & & $-12 \%$ \\
\hline Flexural modulus [GPa] & $54.3 \pm 9.6$ & $83.6 \pm 3.9$ & $44.2 \pm 5.2$ & $49.8 \pm 6.1$ \\
\hline Change in flexural modulus [\%] & & $+54 \%$ & & $+13 \%$ \\
\hline
\end{tabular}




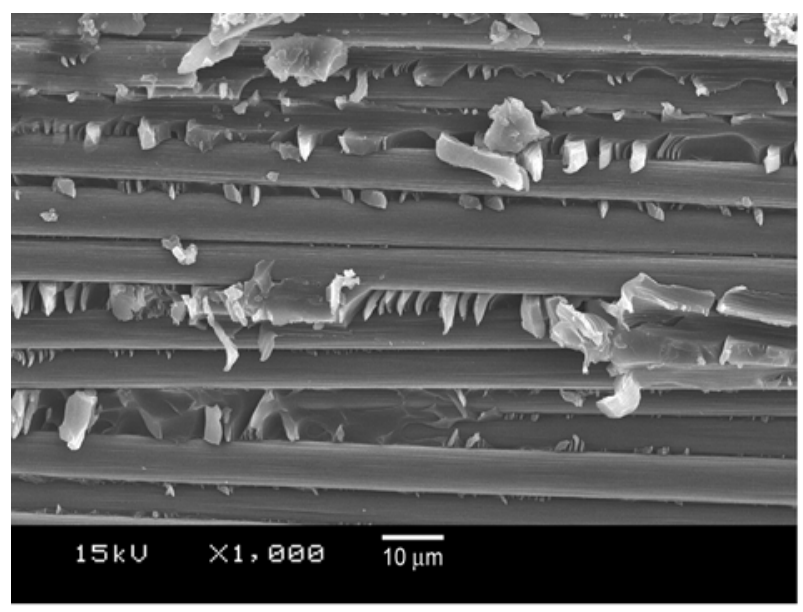

a)

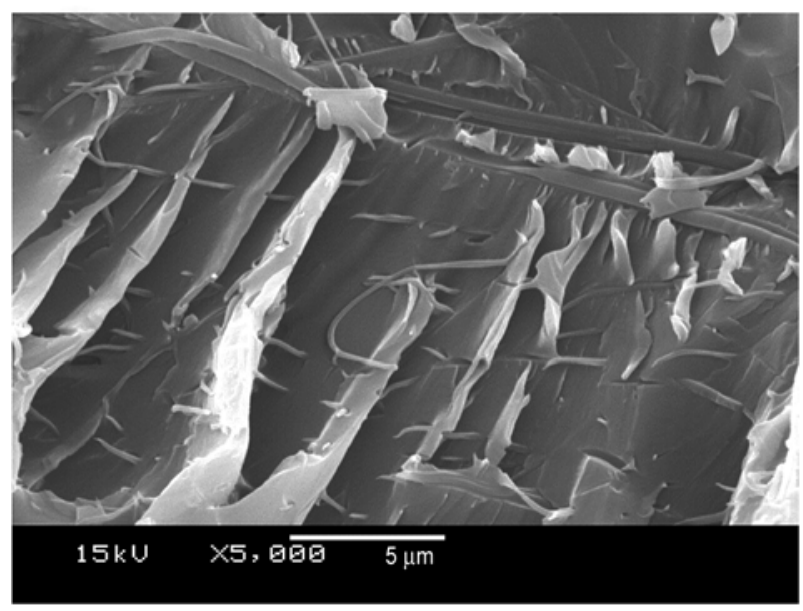

c)

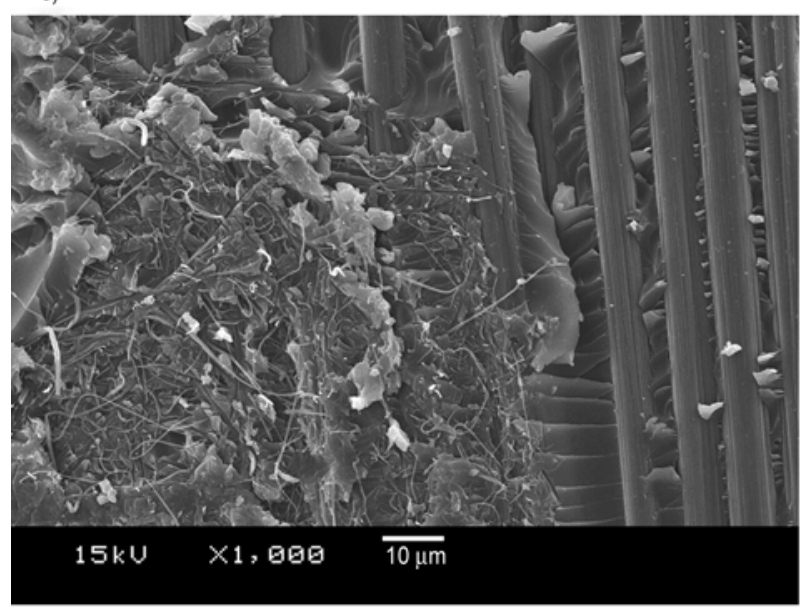

e)

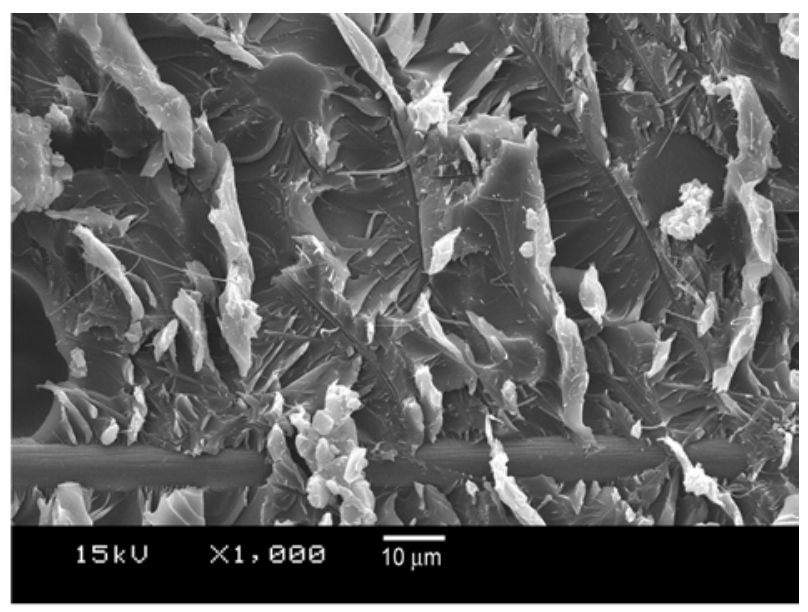

b)

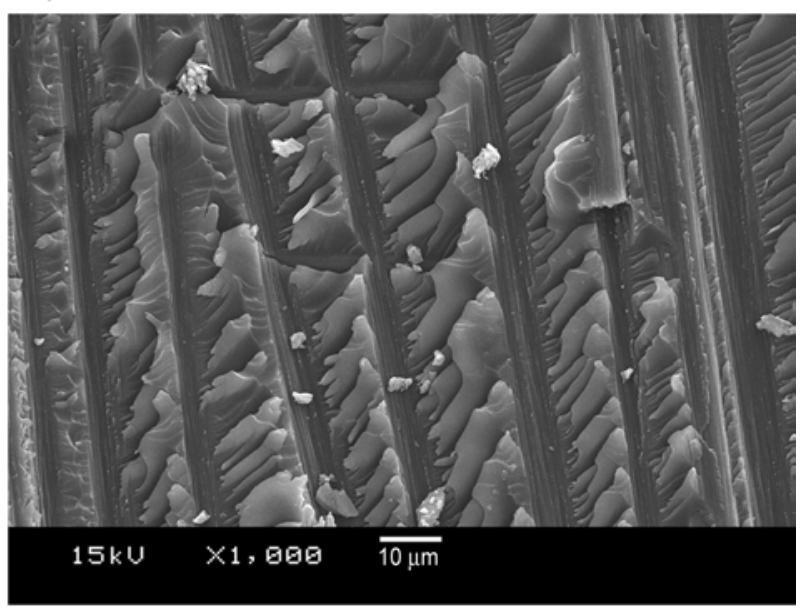

d)

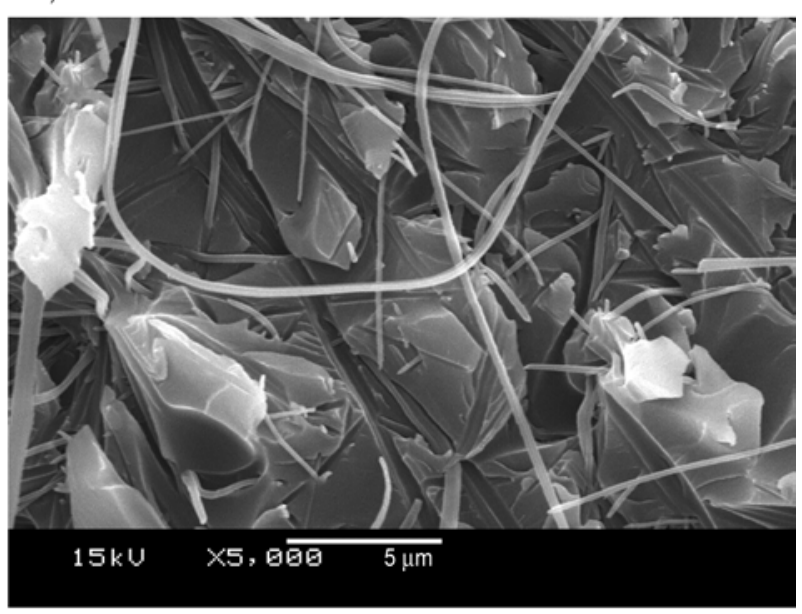

Figure 3. SEM images of the fracture surfaces of ILSS specimens. a) UD CFRP $(\times 1000)$; b) UD CFNRP $(\times 1000)$; c) UD CFNRP $(\times 5000)$; d) W CFRP $(\times 1000)$; e) W CFNRP $(\times 1000)$; f) W CFNRP $(\times 5000)$; W: woven reinforcement, UD: unidirectional fabric reinforcement

forced composite, broken nanofibers were observed, and there were some nanofibers that were still bonded to the matrix material and could stop crack propagation. Therefore, the nanofibers actively participated in load distribution, and plastic deformation could occur. In the case of the woven fabricreinforced composites, the nanofibers debonded from the matrix and did not break. Because the surface was quite structured, a partial load distribution effect occurred, but in this case, the load distribution was less effective than in the case of the UD reinforcement. Because the preparation methods and the applied matrix were the same, the differences observed were caused by the structure of the 
composites. In the ILSS measurement, theoretically, there is pure shear stress between the layers of composites. In practice, however, the stress state also depends on the type of load transfer surface exhibited by composites. In the case of the UD reinforcement, the surface was approximately flat, but that of the woven fabric was wavy and uneven due to the shape of the weft and warp yarns entwining one another, leading to a more complex geometry and stress state between layers. These differences also manifested themselves in the smaller increase in the ILSS values.

\subsection{Flexural behavior}

The flexural properties of the composites varied more significantly (Table 2). At low deformation, the effect of the nanofibers was outstanding: the modulus increased by 54 and $13 \%$ in the UD and woven fabric reinforcements, respectively, which can be explained by the fact that in the nanofiber-tough-

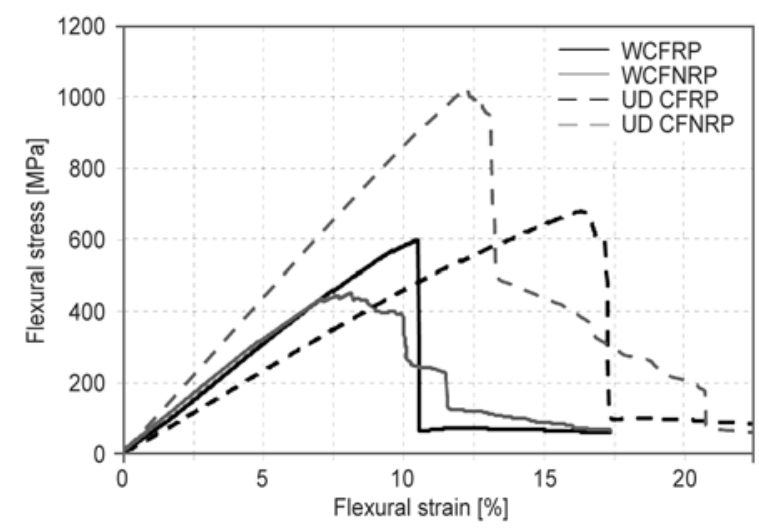

Figure 4. Typical flexural curves of the prepared composites

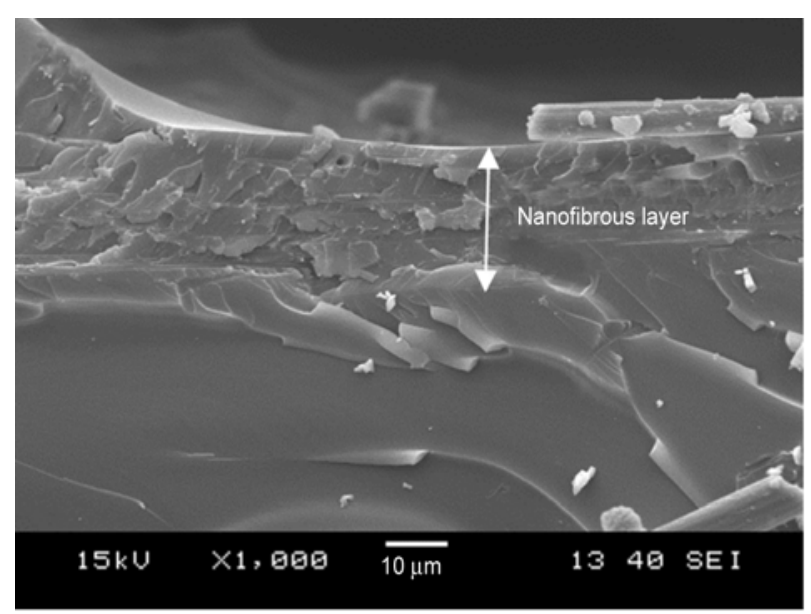

a) ened composites, the nanofibers could transfer the load toward the carbon fibers; thus, the utilization of carbon fibers was enhanced. However, the UD composites showed an increase in flexural strength when nanofibers were also applied, but this increase was not as high as that for the modulus. In the woven fabric reinforcement, the presence of nanofibers reduced the flexural strength values. To explain this behavior, the failure process must be examined. Typical failure curves are shown in Figure 4. Without nanofibers, the damage process of the specimens was rapid; when nanofibers were applied, failure gradually occurred. In the latter case, the layers broke independently one after the other. This phenomenon was confirmed by visual and acoustic observations of the damage process.

Figure 5a shows how the nanofibrous layer affected crack propagation. As cracks reached the nanofibrous part of the composite, the number of fracture trails increased and the surface became more structured, indicating an increase in toughness.

In Figure 5b, the arrow shown points to a nanofiber. The good adhesion of the nanofiber and matrix is indicated by their good physical contact after the composite was broken. The fracture around the nanofiber shows that the load was absorbed by the nanofiber and distributed throughout the matrix (crack propagation was blocked).

\subsection{Charpy impact test}

The results of the impact tests are shown in Table 3. By incorporating nanofibers, the initiation energy and the energy to maximum force increased in all cases. It can be concluded that in the Charpy Ep tests,

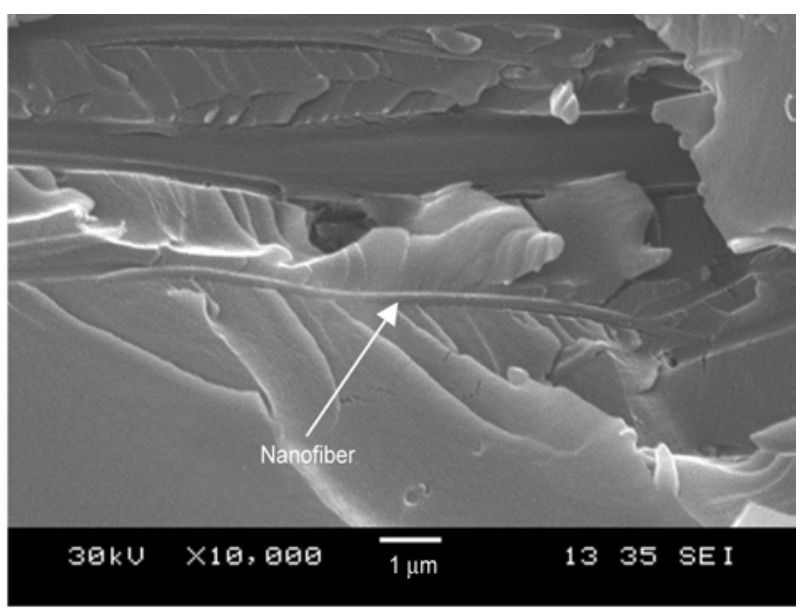

b)

Figure 5. SEM images of the fracture surfaces of nanofiber-toughened flexural specimens after three-point bending tests. a) woven reinforced sample with a thin layer of nanofibers, b) adhesion between a nanofiber and matrix. 
Table 3. Summary of Charpy test and I-FWIT results. Fn: face of the specimen is hit normal direction to the direction of fibers. Ep: edge of the specimen is hit parallel to the fiber reinforcement plies.

\begin{tabular}{|l|l|c|c|c|c|c|c|}
\hline & & UD CFRP & UD CFNRP & Change & W CFRP & W CFNRP & Change \\
\hline Charpy Fn & Initiation energy $\left[\mathrm{kJ} / \mathrm{mm}^{2}\right]$ & $65.7 \pm 4.6$ & $68.2 \pm 5.9$ & $+4 \%$ & $116 \pm 25$ & $133 \pm 24$ & $+14 \%$ \\
\hline Charpy Fn & Total break energy $\left[\mathrm{kJ} / \mathrm{mm}^{2}\right]$ & $80.5 \pm 9.9$ & $90.8 \pm 4.9$ & $+13 \%$ & $130 \pm 15$ & $149 \pm 23$ & $+15 \%$ \\
\hline Charpy Ep & Initiation energy $\left[\mathrm{kJ} / \mathrm{mm}^{2}\right]$ & $24.1 \pm 3.1$ & $35.5 \pm 10.5$ & $+47 \%$ & $37.7 \pm 20.1$ & $153 \pm 40.6$ & $+306 \%$ \\
\hline I-FWIT & Total break energy $\left[\mathrm{kJ} / \mathrm{mm}^{2}\right]$ & $115 \pm 11.6$ & $148 \pm 16.8$ & $+29 \%$ & $158 \pm 37.0$ & $227 \pm 59.5$ & $+44 \%$ \\
\hline I-FWIT & Energy to maximum force [J/mm] & N/A & N/A & N/A & $1.540 \pm 0.320$ & $2.520 \pm 1.040$ & $+64 \%$ \\
\hline I-FWIT & Total break energy [J/mm] & N/A & N/A & N/A & $8.590 \pm 0.190$ & $8.07 \pm 0.58$ & $-6 \%$ \\
\hline I-FWIT & $\begin{array}{l}\text { Absorbed energy at subcritical } \\
\text { impact [J/mm] }\end{array}$ & N/A & N/A & N/A & $0.267 \pm 0.033$ & $0.349 \pm 0.036$ & $+31 \%$ \\
\hline
\end{tabular}

the presence of nanofibers resulted in a major improvement in the initiation energy relative to that observed in the Charpy Fn tests for both the UDand woven fabric-reinforced composites. The most significant increase was observed for the woven fabric-reinforced composite (W CFNRP) in the Charpy Ep impact test. As the composite was hit parallel to the plane of the reinforcing layers and the toughening interleaves, at the moment of impact, the entire area of the interleaves immediately became

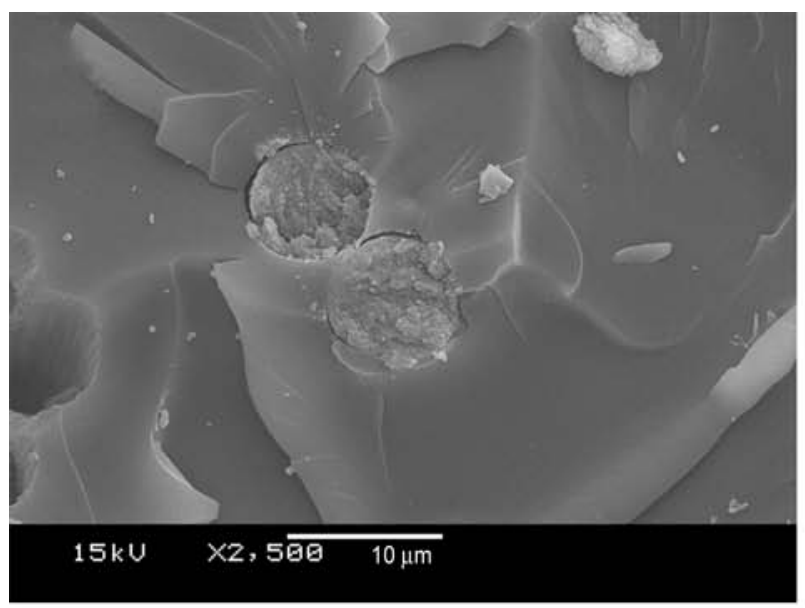

a)

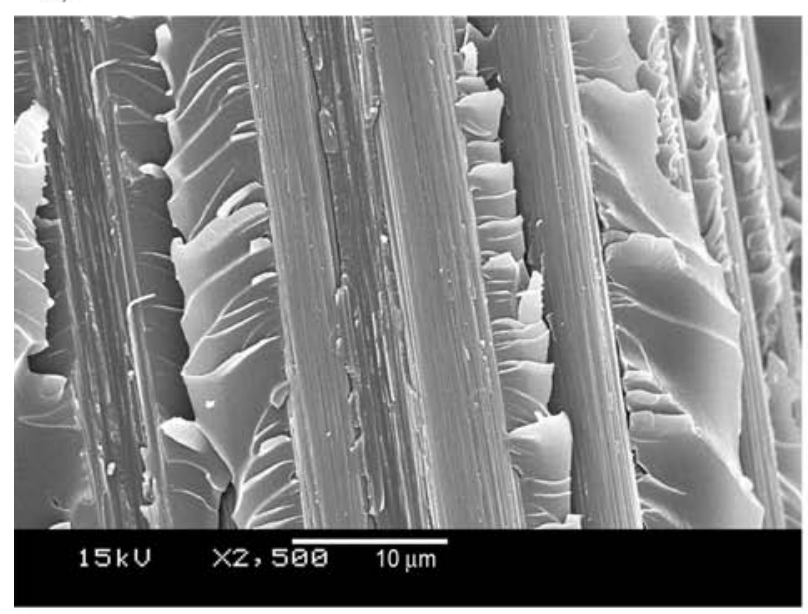

c) involved in bearing the applied load and nanofibers exerted their effects throughout the entire shear plane. In addition to being able to adsorb the impact energy via plastic deformation, these nanofibrous layers could transfer the load toward the adjacent carbon fiber layers. In the quasi-static ILSS tests of the woven reinforced composites, waviness of the interacting surfaces led to a moderate increase in ILSS. In this case, when the load transfer was instantaneous, the more complex geometry and larger area

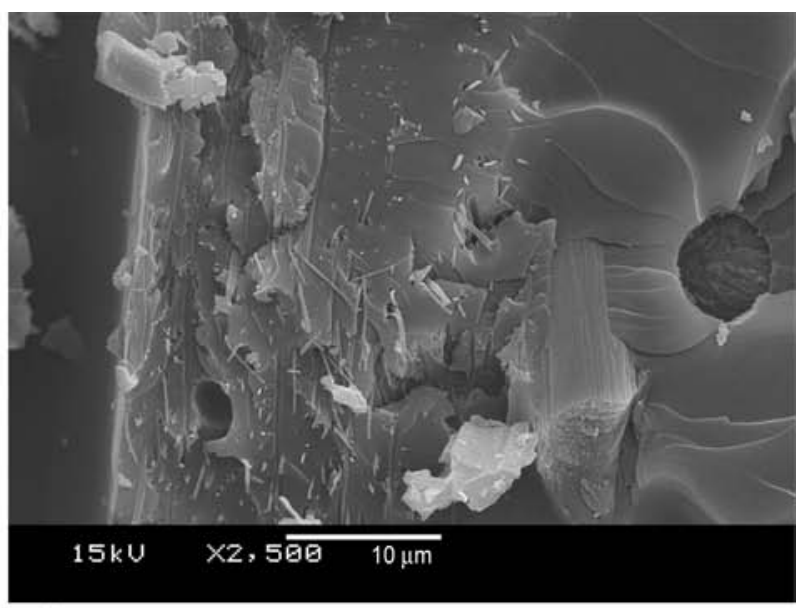

b)

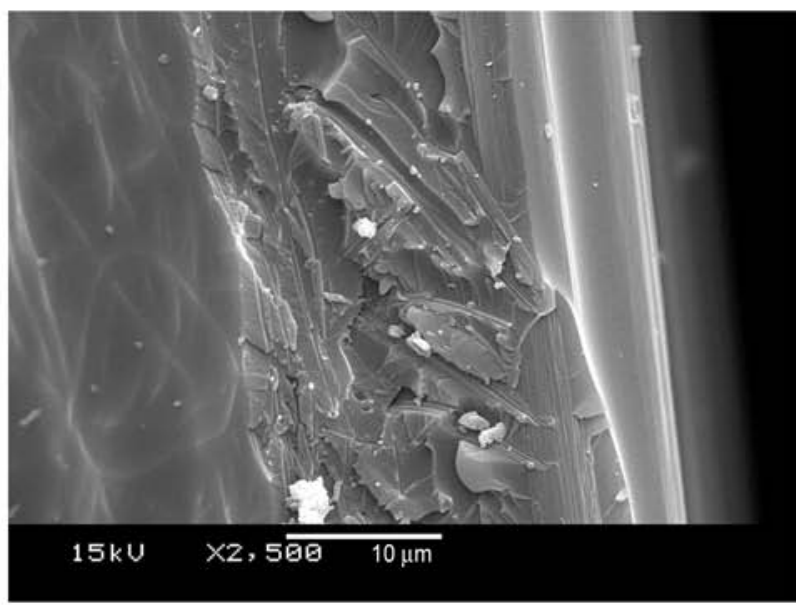

d)

Figure 6. SEM images of surface fractures of Charpy Fn impact specimens. a) UD CFRP; b) UD CFNRP; c) W CFRP; d) W CFNRP; W: woven reinforcement, UD: unidirectional fabric reinforcement. 
of the interacting surfaces resulted in an improved load-bearing ability. On the other hand, in the Charpy Fn test and I-FWIT, only the surfaces near the impact zone were involved in load transfer, and in this case, the stress field was continuously formed and changed during the damage process both in time and space.

Figure 6 shows SEM images of the fracture surfaces of the Charpy Fn impact specimens. In the nanofiber-reinforced samples (Figure 6b; 6d), nanofibers were present on the fracture surfaces and microfiber breakage could also be observed. Nanofiber layers with broken nanofibers can clearly be observed in the figures as distinct zones: to the left of the center of Figure $6 \mathrm{~b}$ and at the center of Figure $6 \mathrm{~d}$. In the nanofiber-containing region, which is approximately $20 \mu \mathrm{m}$ wide, broken nanofibers and a tough damage surface indicate good adhesion between the matrix and nanofibers. In the reference sample (Figure 6c), the matrix was separated from the fibers in small pieces, forming a rough interlaminar fracture surface. SEM images confirm that nanofibers played an important role in the damage process because they effectively blocked crack propagation.

\subsection{Instrumented falling weight impact test}

The total absorbed energy showed a moderate increase, except in the I-FWIT measurements (Table 3), in which a slight decrease was observed. In the I-FWIT, the energy to maximum force significantly increased by more than $60 \%$ and the adsorbed energy at subcritical impact improved by more than $30 \%$, demonstrating the increased resistance of the nanofiber-toughened composites against dynamic stress. Overall, the results of the I-FWITs showed that if there were nanofibers in the composites, then they could stop the crack propagation process, allowing for a higher energy to maximum force. Because nanofibers are able to distribute the applied load, the nanocomposite layers may act as energy storage materials. After the breaking of these layers, the stored energy is released and the composite itself breaks more rapidly than the reference material. Thus, despite a higher energy to maximum force, the total absorbed energy decreases only slightly. This speculation corresponds well with the results of the three-point bending tests.

\section{Conclusions}

The toughening effect of nanofibrous interlayers in carbon fiber-reinforced structures was proven. Beneficial changes occurred not only in the static but also in the impact behavior of the composites. Under static loads, the positive effects were more significant in the UD-reinforced composites, for which the interlaminar shear strength increased by $11 \%$ and the flexural strength and modulus by 21 and $54 \%$, respectively. This improvement was explained by the presence of nanofibers that could transfer the applied load toward the carbon fibers. The greatest improvements were observed in the Charpy Ep test results of the woven reinforced composites, in which the initiation energy increased three-fold. Falling dart impact tests revealed that the energy to maximum force increased by $64 \%$ in this material. These outstanding improvements are explained by the energy-absorption behavior of the nanofibrous composite layer.

\section{Acknowledgements}

This research was supported by the Czech-Hungarian intergovernmental research agency KONTAKT (CZ-07/2009) and by funding from the European Union's Seventh Framework Programme (FP7/2007-2013) for the Clean Sky Joint Technology Initiative under grant agreement no 270599.

This work is related to the scientific program of the 'Development of quality-oriented and harmonized $\mathrm{R}+\mathrm{D}+\mathrm{I}$ strategy and functional model at BME' and to the New Széchenyi Plan (Project ID: TÁMOP-4.2.1/B-09/1/KMR-2010-0002 and TÁMOP- 4.2.2.B-10/1-2010-0009). This research was also supported by the Hungarian Research Fund (OTKA K100949, OTKA PD105564). This study is dedicated to the memory of our friend and student: Adam Papp.

\section{References}

[1] Subbiah T., Bhat G. S., Tock R. W., Parameswaran S., Ramkumar S. S.: Electrospinning of nanofibers. Journal of Applied Polymer Science, 96, 557-569 (2005). DOI: 10.1002/app.21481

[2] Nagy Z. K., Balogh A., Vajna B., Farkas A., Patyi G., Kramarics Á., Marosi Gy.: Comparison of electrospun and extruded soluplus ${ }^{\circledR}$-based solid dosage forms of improved dissolution. Journal of Pharmaceutical Sciences, 101, 322-332 (2012).

DOI: $10.1002 /$ jps.22731

[3] Zhuo H. T., Hu J. L., Chen S. J.: Coaxial electrospun polyurethane core-shell nanofibers for shape memory and antibacterial nanomaterials. Express Polymer Letters, 5, 182-187 (2011).

DOI: $\underline{10.3144 / \text { expresspolymlett.2011.16 }}$ 
[4] del Valle L. J., Diaz A., Royo M., Rodriguez-Galan A., Puiggali J.: Biodegradable polyesters reinforced with triclosan loaded polylactide micro/nanofibers: Properties, release and biocompatibility. Express Polymer Letters, 6, 266-282 (2012). DOI: 10.3144/expresspolymlett.2012.30

[5] Li G., Li P., Zhang C., Yu Y., Liu H., Zhang S., Jia X., Yang X., Xue Z., Ryu S.: Inhomogeneous toughening of carbon fiber/epoxy composite using electrospun polysulfone nanofibrous membranes by in situ phase separation. Composites Science and Technology, 68, 987994 (2008).

DOI: 10.1016/j.compscitech.2007.07.010

[6] Tong L., Mouritz A. P., Bannister M. K.: 3D fibre reinforced polymer composites. Elsevier, Oxford (2002).

[7] Wu X-F., Yarin A. L.: Recent progress in interfacial toughening and damage self-healing of polymer composites based on electrospun and solution-blown nanofibers: An overview. Journal of Applied Polymer Science, 130, 2225-2237 (2013).

DOI: $10.1002 / a p p .39282$

[8] Czél G., Czigány T.: A study of water absorption and mechanical properties of glass fiber/polyester composite pipes - Effects of specimen geometry and preparation. Journal of Composite Materials, 42, 2815-2827 (2008).

DOI: $10.1177 / 0021998308096668$

[9] Chen S. F., Jang B. Z.: Fracture behaviour of interleaved fiber-resin composites. Composites Science and Technology, 41, 77-97 (1991).

DOI: 10.1016/0266-3538(91)90054-S

[10] Aksoy A., Carlsson L. A.: Interlaminar shear fracture of interleaved graphite/epoxy composites. Composites Science and Technology, 43, 55-69 (1992). DOI: 10.1016/0266-3538(92)90133-N

[11] Todo M., Jar P. B., Takahashi K.: Initiation of a modeII interlaminar crack from an insert film in the endnotched flexure composite specimen. Composites Science and Technology, 60, 263-272 (2000). DOI: 10.1016/S0266-3538(99)00119-0

[12] Kishi H., Kuwata M., Matsuda S., Asami T., Murakami A.: Damping properties of thermoplastic-elastomer interleaved carbon fiber-reinforced epoxy composites. Composites Science and Technology, 64, 2517-2523 (2004).

DOI: 10.1016/j.compscitech.2004.05.006

[13] Godara A., Gorbatikh L., Kalinka G., Warrier A., Rochez O., Mezzo L., Luizi F., van Vuure A. W., Lomov S. V., Verpoest I.: Interfacial shear strength of a glass fiber/ epoxy bonding in composites modified with carbon nanotubes. Composites Science and Technology, 70, 1346-1352 (2010).

DOI: $10.1016 /$ j.compscitech.2010.04.010

[14] Deng F., Lu W., Zhao H., Zhu Y., Kim B-S., Chou TW.: The properties of dry-spun carbon nanotube fibers and their interfacial shear strength in an epoxy composite. Carbon, 49, 1752-1757 (2011).

DOI: $10.1016 /$ j.carbon.2010.12.061
[15] Tan K. T., Watanabe N., Yoshimura A., Iwahori Y.: Validation of delamination reduction trend for stitched composites using quasi-static indentation test. in 'Proceedings of the $15^{\text {th }}$ European Conference on Composite Materials (ECCM-15), Venice, Italy' 282, p7 (2012).

[16] Zhang X., Hounslow L., Grassi M.: Improvement of low-velocity impact and compression-after-impact performance by z-fibre pinning. Composites Science and Technology, 66, 2785-2794 (2006). DOI: 10.1016/j.compscitech.2006.02.029

[17] Kornmann X., Rees M., Thomann Y., Necola A., Barbezat M., Thomann R.: Epoxy-layered silicate nanocomposites as matrix in glass fibre-reinforced composites. Composites Science and Technology, 65, 2259-2268 (2005).

DOI: 10.1016/j.compscitech.2005.02.006

[18] Dzenis Y. A., Reneker D. H.: Delamination resistant composites prepared by small diameter fiber reinforcement at ply interfaces. U.S. Patent 6265333, USA (2001).

[19] Zhang J., Lin T., Wang X.: Electrospun nanofibre toughened carbon/epoxy composites: Effects of polyetherketone cardo (PEK-C) nanofibre diameter and interlayer thickness. Composites Science and Technology, 70, 1660-1666 (2010). DOI: 10.1016/j.compscitech.2010.06.019

[20] Chen Q., Zhang L., Rahman A., Zhou Z., Wu X-F., Fong H.: Hybrid multi-scale epoxy composite made of conventional carbon fiber fabrics with interlaminar regions containing electrospun carbon nanofiber mats. Composites Part A: Applied Science and Manufacturing, 42, 2036-2042 (2011). DOI: 10.1016/j.compositesa.2011.09.010

[21] Chen Q., Zhao Y., Zhou Z., Rahman A., Wu X-F., Wu W., Xu T., Fong H.: Fabrication and mechanical properties of hybrid multi-scale epoxy composites reinforced with conventional carbon fiber fabrics surfaceattached with electrospun carbon nanofiber mats. Composites Part B: Engineering, 44, 1-7 (2013).

DOI: 10.1016/j.compositesb.2012.09.005

[22] Sihn S., Kim R. Y., Huh W., Lee K-H., Roy A. K.: Improvement of damage resistance in laminated composites with electrospun nano-interlayers. Composites Science and Technology, 68, 673-683 (2008). DOI: 10.1016/j.compscitech.2007.09.015

[23] Zhang J., Yang T., Lin T., Wang C. H.: Phase morphology of nanofibre interlayers: Critical factor for toughening carbon/epoxy composites. Composites Science and Technology, 72, 256-262 (2012). DOI: $10.1016 /$ j.compscitech.2011.11.010

[24] Jirsak O., Sanetrnik F., Lukas D., Kotek V., Martinova L., Chaloupek J.: A method of nanofibres production from a polymer solution using electrostatic spinning and a device for carrying out the method. International Patent WO 2005/024101 A1 (2005). 
[25] Akangah P., Lingaiah S., Shivakumar K.: Effect of Nylon-66 nano-fiber interleaving on impact damage resistance of epoxy/carbon fiber composite laminates. Composite Structures, 92, 1432-1439 (2010). DOI: $10.1016 /$ j.compstruct.2009.11.009

[26] Liao C-C., Wang C-C., Chen C-Y., Lai W-J.: Stretching-induced orientation of polyacrylonitrile nanofibers by an electrically rotating viscoelastic jet for improving the mechanical properties. Polymer, 52, 2263 2275 (2011).

DOI: $10.1016 /$ j.polymer.2011.03.018
[27] Nataraj S. K., Yang K. S., Aminabhavi T. M.: Polyacrylonitrile-based nanofibers - A state-of-the-art review. Progress in Polymer Science, 37, 487-513 (2012). DOI: 10.1016/j.progpolymsci.2011.07.001

[28] Molnár K., Koštáková E., Vas L. M.: Preparation of composites reinforced with ' in situ' electrospun fibres. in 'Proceedings of the European Conference on Composite Materials (ECCM-14), Budapest, Hungary' 116-ECCM14, p7 (2010). 